\title{
Dementia management: an occupational therapy home-based intervention for caregivers.
}

\author{
Mary A. Corcoran \\ Thomas Jefferson University \\ Laura N. Gitlin \\ Thomas Jefferson University
}

Follow this and additional works at: https://jdc.jefferson.edu/otfp

Part of the Occupational Therapy Commons

Let us know how access to this document benefits you

\section{Recommended Citation}

Corcoran, Mary A. and Gitlin, Laura N., "Dementia management: an occupational therapy homebased intervention for caregivers." (1992). Department of Occupational Therapy Faculty Papers. Paper 49.

https://jdc.jefferson.edu/otfp/49

This Article is brought to you for free and open access by the Jefferson Digital Commons. The Jefferson Digital Commons is a service of Thomas Jefferson University's Center for Teaching and Learning (CTL). The Commons is a showcase for Jefferson books and journals, peer-reviewed scholarly publications, unique historical collections from the University archives, and teaching tools. The Jefferson Digital Commons allows researchers and interested readers anywhere in the world to learn about and keep up to date with Jefferson scholarship. This article has been accepted for inclusion in Department of Occupational Therapy Faculty Papers by an authorized administrator of the Jefferson Digital Commons. For more information, please contact: JeffersonDigitalCommons@jefferson.edu. 


\section{Dementia Management: An Occupational Therapy Home-Based Intervention for Caregivers}

\author{
Mary A. Corcoran, Laura N. Gitlin
}

Key Words: Alzheimer's disease $\bullet$ caregivers

This paper describes an occupational therapy intervention designed for family caregivers of persons with dementia. The intervention, based on the framework. of a competence-environmental press model and the principle of collaboration, was implemented during 5 home visits. Each visit was designed to build caregiving skills through collaboration in identifying problem areas. developing and implementing environmental strategies, and modifying management approaches. A case vignette illustrales the therapeutic process and outcomes. The theoretical rationale and structure of the intervention and innovative documentation for evaluation of the theoretic process are also presented.

Mary A. Corcoran, phn is Assistant Professor, Thomas Jefferson Universicy, Departmenc of Occupational Therapy, 130 South 9th Strcet, Suite 820, Philadelphia, Pennsylvania 19107.

Laura N. Gitlin, PhD. is Associate Professor and Research Coorclinator, Thomas Jefferson University. Department of Occupational Therapy, Philaclelphia, Pennsylvania.

7his arich was accepled for publicalion April 20. 1992.
$\mathrm{N}$

ational estimates indicate that 4 million Americans have Alzheimer disease and that this number will rise as the older population increases. Extensive research has documented the profound consequences of Alzheimer disease for the person as well as for family and friends who continue to provide more than $80 \%$ of the long-term care and management of the disease process (Pepper Commission, 1990; Select Subcommittee on Aging, 1987). Such daily management issues as wandering, agitation, violence, aggression, and difficulties with self-care activities have been shown to have dramatic physical and psychological consequences for informal caregivers. This paper presents a home-based occupational therapy intervention designed to improve caregiver skill in the management of the behavioral or secondary symproms exhibited by a spouse with dementia. The rationale for the intervention, a description of each therapeutic visit, an innovative documentation form, and a case to illustrate the intervention process are provided. Presented elsewhere are the detailed explanation of the conceptual components of the intervention (Corcoran \& Gitlin, 1991), the study methods and outcomes (Gitlin \& Corcoran, 1991a), and a program used to train occupational therapy students in the delivery of the intervention (Gitlin \& Corcoran, 1991b).

\section{Background}

The intervention presented in this paper addresses three critical issues that have emerged from caregiver and health services research: (a) the need for theory-based treatment approaches, (b) the importance of developing strategies to manage the behavioral outcomes of Alzheimer disease, and (c) the importance of developing home-based service strategies that reflect the needs of caregivers.

\section{Need for Theory-Based Treatment Approaches}

Although caregiver interventions have recently proliferated, they still lack a theoretical base (Gallagher, 1985; Haley, Brown, \& Levine, 1987). Reported interventions have included stress management, education, group support programs (Whitlatch, Zarit, \& von Eye, 1991; Zarit, Anthony, \& Boutsetts, 1987), personal and group counseling programs (Gallagher, Rappaport, \& Benedict, 1985; Lovett \& Gallagher, 1988; Toseland, Rossiter, \& Labrecuue. 1989), relaxation and meditation (Gendron et al., 1986), respite care (Burdz, 1988; Lawton, Brody, \& Saperstein, 1989), and problem-solving groups (Silven et al.. 1986). These interventions have evolved in response to a body of literature that identifies stress as a major contributor to the health and well-being of caregivers. Although these programs provide critical support to caregivers, they do not reflect the complexity of the experiences and the breadth of issues that caregivers indicate as 
problematic. Furthermore, research by Dura and KiecoltGlaser (1990) suggests that caregivers who choose not to participate in on-site training and educational programs may differ greatly in their needs and care approaches from those who require home-based services. Alternative interventions that are founded in concepts broader than stress and that are sensitive to caregivers' concerns are evidently necessary.

\section{Need to Develop Management Strategies}

Because dementia is irreversible and progressive, caregivers' needs often change and expand over time. Recent studies have identified the development of caregivers' management abilities as a meaningful approach for addressing diverse caregiver needs encountered over time (Clark \& Rakowski, 1983; Corbin \& Strauss, 1988; Corcoran \& Gitlin, 1991; Crossman, London, \& Barry, 1981; Gallagher, 1985; Pinkston \& Linsk, 1986; Smith, Smith, \& Toseland, 1991; Toseland et al., 1989). Ethnographic research has also revealed that caregivers create meaningful, effective solutions to daily care problems, but seek reinforcement and additional skills to refine their efforts (Hasselkus, 1988). These findings underscore the importance of helping caregivers develop effective problemsolving skills to manage the diverse behavioral manifestations of dementia.

\section{Need for Personalized Inteventions}

An extensive body of literature indicates that the emotional, physical, and social consequences of caregiving differ based on gender, familial relationship, and cultural background (Anthony-Bergstone, Zarit, \& Gatz, 1988; Brody, 1981; Hasselkus, 1988; Pruchno, Michaels, \& Potashnik, 1990; Rodeheaver \& Datan, 1988; Sherman, Ward, \& LaGory, 1988; Wilson, 1990; Young \& Kahana, 1989). These differences influence approaches to managing care, especially problem-solving skills, use of formal and informal supports, degree of upset experienced with dementia-related behaviors, and sense of personal efficacy derived from caregiving (Barusch \& Spaid, 1989; Young \& Kahana, 1989). Furthermore, the group education and counseling format used in most interventions may be inappropriate for male caregivers and others from diverse cultural backgrounds who traditionally have not participated in such groups (Barusch \& Spaid, 1989; Edwards \& Baum, 1990; Kaye \& Applegate, 1990; Miller, 1987; Wilson, 1990).

This literature suggests that health services for caregivers must be flexible to address each caregiver's specific needs, style of care, and values. Services that are client driven and derived through working with a health care provider may effectively support caregivers (Gitlin \& Corcoran, 1991b; Hasselkus, 1988; Perlman, 1973). Homebased services, in particular, must reflect the caregiver's perceptions of need and support his or her values and style of care (Hasselkus, 1988; Levine, Corcoran, \& Gitlin, in press). Treatment strategies that incorporate caregivers' values and personal goals have been shown to be more efficient and effective for older disabled adults (Chiou \& Burnett, 1985; Perlman, 1973; Shelton, Jeppson, \& Johnson, 1989).

\section{Theoretical Framework}

A competence--environmental press model (Ansello, King, \& Taler, 1986; Lawton, 1989b; Lawton \& Nahemow, 1973) provides the conceptual framework for developing the therapeutic strategies within the intervention described below. This model suggests that many behavioral manifestations of dementia may be controlled or minimized by environmental manipulations that lower the press for persons with declining levels of competence. Press refers to the external forces of the environment that influence the functioning of a person with a specific level of competence. The model suggests that enhancing a caregiver's ability to modify environmental press may have two consequences. First, it may minimize difficult behaviors manifested by the person with dementia. Second, the incorporation of environmental strategies may expand caregiver problem-solving abilities and thus improve the caregiver's sense of efficacy in managing daily problems.

Research findings from studies that used theories of person-environment fit have underscored that the environment can promote or restrict independent behavior and positive affect (Barris, Kielhofner, Levine, \& Neville, 1985; Lawton, 1989a; Parmalee \& Lawton, 1990; Pynoos, Cohen, David, \& Bernhardt, 1987). Evidence from studies on institutional settings suggests that specially designed environments may reduce behaviors such as wandering, agitation, or restlessness (Corcoran \& Barrett, 1987; Hall \& Buckwalter, 1987; Hiatt, 1982; Kiernat, 1982; Levy, 1987; Paire \& Karney, 1984; Parmalee \& Lawton, 1990). Environmental strategies to control behavior of the person with Alzheimer disease have included removing clutter to reduce agitation and promote cue finding, placing clothing out to decrease confusion and promote independent dressing, and simplifying daily tasks to facilitate participation (Kiernat, 1986; Levy, 1987). Alchough publications tell caregivers how to eliminate environmental barriers (Pynoos, Cohen, \& Lucas, 1988), caregivers have not traditionally received hands-on training in using the environment to control secondary symptoms of dementia.

Therapeutic strategies derived from a competenceenvironmental press framework are designed to alter press and thus realign the competence of the care recipient with environmental expectations. As in Barris et al.'s model (1985), the environment is defined as four hierarchically arranged, interacting layers: (a) objects (physical 
tools or objects in the home), (b) tasks (activities that compose daily routines such as meal preparation and eating), (c) social groups and organizations (family, friends, and neighbors), and (d) culture (values and beliefs that shape care provision in the home). Therapeutic strategies involve manipulating the properties of these layers to achieve a balance between the competence of the person with Alzheimer disease and the pressing environmental forces (Corcoran \& Gitlin, 1991).

Within this theoretical framework, the intervention uses a collaborative therapeutic structure in which the occupational therapist and caregiver develop and implement environmental strategies that address the secondary symptoms of dementia. Collaboration requires that the health professional listen actively and involve the caregiver in identifying problems, planning treatment, and implementing treatment. Within a collaborative framework, treatment becomes contextualized and is shaped by the caregiver's unique needs, goals, preferences, and resources. This approach to treatment enables families to function proactively to manage the influence that chronic illness exerts on their life-style (Corbin \& Strauss, 1988; Hanft, 1989). Occupational therapy efforts respond to, and are shaped by, each caregiver's needs, management style, and environmental resources. This approach to intervention has been identified as a critical step in the development and testing of meaningful services for this population (Haley, 1991; Smith et al, 1991).

\section{Description of Intervention}

The intervention, which involves five home visits in 3 months by a registered occupational therapist, is targeted for caregivers who assist with self-care activities for a spouse with moderate to severe dementia from Alzheimer disease. It was designed to meet caregivers' demonstraced need for instruction in care techniques (Hasselkus, 1988; Smith et al., 1991), major risk of physical and psychological decline (American Association of Retired Persons, 1988), and high probability of insticutionalizing their spouses (Pruchno et al., 1990; Stone, Cafferata, \& Sangl, 1987).

During each visit, the occupational therapist and caregiver work together, first to identify behaviors that present difficult management issues for the caregiver, then to decermine appropriate environmental solutions. This problem-solving activity gives caregivers new strategies to change and control behavior of the person with dementia by manipulating the objects, tasks, or sociocultural components of the environment (Barris er al., 1985; Kiernat, 1982).

In each session, the occupational therapist provides ongoing support and education about dementia and its secondary behavioral symptoms and the availability of support groups and community resources. This ongoing education is contextual in that it responds to the needs of each caregiver and his or her level of knowledge as it emerges during therapeutic exchange. As the intervention progresses, the therapist redirects the caregiver's attention and problem-solving approaches to the elements in the environment that may be exacerbating the behavioral symptoms of dementia. The focus of each visit and the basic activities that occur are described below.

Visit 1. The focus of this visit is to build rapport and establish goals. First, the therapist begins to build a collaborative relationship by facilitating the caregiver's attempts to (a) share his or her perspectives about providing care, (b) identify problems to be addressed, and (c) set goals for the subsequent visits. Second, the therapist reviews current care strategies by observing the interactions between caregiver and care recipient and begins to identify environmental influences on problem behaviors. Although the problem behaviors identified by the caregiver as particularly difficult are the target of Visit 1, the therapist also attempts to observe other care strategies to assess the caregiver's general problem-solving approach and use of the environment.

Visit 2. This visit has three objectives, in addition to the continuation of observations and dialogue to build a collaborative relationship. First, the therapist indicates specific environmental influences on the problem behaviors identified in Visit 1. Second, the therapist introduces information regarding dementia, role modeling of specific care activities, and use of the environment as a treatment modality. Third, the caregiver and therapist develop a plan to address specific problem behaviors and identify the initial steps to be implemented by the caregiver. An example of such behavior would be a care recipient's inability to choose appropriate articles of clothing and don them in the correct sequence. The plan may involve working with the caregiver to eliminate extraneous articles of clothing from sight (objects layer), match the physical assistance provided in dressing with the care recipient's fluctuating needs (task layer), and provide verbal cues regarding socially appropriate clothing for the events of the day (social and cultural layers).

Visit 3. During this visit, the therapist and caregiver review their plan and the initial steps implemented by the caregiver berween Visits 2 and 3. They examine the caregiver's perceptions and recollections of the plan's effect on the frequency and severity of problem behaviors and explore how the caregiver felt about the modifications. On the basis of this review, the caregiver and therapist further refine the plan, use it to develop detailed environmental strategies for managing other problem behaviors, and agree on a time frame for implementation.

Visit 4. During this visit, the therapist assists the caregiver in further refining specific care strategies. The therapist continues to engage in role modeling and education but begins to release ownership of management decisions to the caregiver. To facilitate the caregiver's skills and sense of efficacy, the therapist encourages the 
caregiver to make more inclependent, informed management decisions. Finally, the problem-solving process used to develop the plan is identified and generalized to other problems.

Visit 5. An important task of the final intervention visit is the review of the problem-solving process that the caregiver has used to approach specific problem behaviors. Other tasks may include final modifications of specific strategies and refinement of caregiver's techniques. Closure includes confirmation of the caregiver's skills and a discussion of the application of environmental strategies to future problems. The following case illustration shows the progression of the intervention from building rapport, collaboratively identifying problem areas, and developing and implementing environmental strategies to reevaluating, modifying, and supporting management approaches

\section{Case Illustration}

For several years, Mrs. C. has been caring for her husband, who is moderately impaired because of Alzheimer disease. Mrs. C. is an anxious person who has frequent asthma attacks as a result of stress. She expresses fear of her husband because he has a tendency to become paranoid and suspicious. For this reason, Mrs. C. scheduled all the initial intervention appointments for times when her husband would be away from home.

Mrs. C. and the therapist spent most of Visit 1 exploring Mrs. C.'s perspectives on the demands of her caregiving role, her response to those demands, and the goals of the intervention. Mrs. C. reported that three major issues troubled her: her husband's tendency to repeat questions, his resistance to bathing, and her own uncertainty about Alzheimer disease and its management. The therapist explored with Mrs. C. how she managed each problem area. Mrs. C. explained that her solutions to the first two problems involved either yelling at her husband or ignoring him to avoid a fight. Either way, she was ineffective in managing his problem behaviors, as evidenced by her high stress levels and his lack of personal hygiene. The therapist suggested several possible environmental influences on $\mathrm{Mr}$. C. 's behavior, such as lack of an established bathing routine (task layer) and absence of visual cues in objects needed for bathing (objects layer). These were confirmed or refuted by Mrs. C. The two agreed to establish a regular routine, identify sources of information about Alzheimer disease and its management (social groups layer), and develop an atmosphere of calm in the home (task layer). Mrs. C. instructed the therapist to meet with her in her husband's absence for the next visit.

During Visit 2, Mrs. C. and the therapist developed a plan based on the discussion from Visit 1. With the therapist's guidance, Mrs. C. decided to place a written schedule on the dining room table each morning and to direct her husband to the kitchen sink for bathing at the same time each day (task layer). She also agreed to try to answer his repetitive questions promptly, but just once and in a calm voice (task layer). Instead of responding to a repeated question, Mrs. C. decided to redirect her husband (task layer) and to leave the room when she felt aggravated. The therapist role-played these techniques with Mrs. C. to clarify them and gave her a copy of The 36Hour Day (Mace \& Rabins, 1981).

During Visit 3, Mrs. C. and the therapist reviewed their plan and the initial steps that Mrs. C. had implemented. Mrs. C. reported that she had shouted at her husband much less during the interim between visits. She had decided to direct her husband to the sink for bathing only on Sundays, after he shaved, because this had been his normal routine for years (task layer). The daily schedule was not only in place, but Mrs. C. had taken the initiative to write it in large print on a bright piece of paper (objects layer). In this way, Mrs. C. modified the therapist's suggestions to reduce the possibility that $\mathrm{Mr}$. C. would misinterpret her verbal instructions. A final objective of this visit was to refine and expand Mrs. C.'s management techniques, so the therapist began to help Mrs. C. explore how the environment around the sink could be adapted to encourage her husband's independent bathing.

By Visit 4, Mrs. C. had independently set up the sink with a towel hanging nearby and had placed the soap in a bright container to increase visibility (objects layer). She happily reported that she had not needed to give her husband instructions after she calmly reminded him to remove his shirt for bathing (task layer). By this time, Mrs. C. had eliminated her ineffective solutions of yelling at her husband or ignoring him. Her ability to remain calm had improved and she had established the habit of leaving the room when upset. During this visit, the therapist and Mrs. C. discussed the success of a regular routine and calm atmosphere, refined her environmental modifications, and began to generalize these techniques to emerging problems such as incontinence. Mrs. C. had purchased her own copy of The 36-Hour Day (Mace \& Rabins, 1981) and had called her physician for a referral to a dementia specialist (social groups layer). Because the physician had refused to make a referral, Mrs. C. requested more information about community resources from the therapist.

During Visit 5, Mrs. C. reported that she had contacted a local hospital about caregiver education classes and listed four other community resources of which she was aware (social groups layer). Her husband's emerging incontinence had not been a problem during the past week, but Mrs. C. was uncertain about why it had abated. The therapist reviewed Mrs. C.'s problem-solving approach and explored how Mr. C.'s incontinence might have been positively influenced as a result of the regular routine and approving attitude. By Visit 5, Mrs. C. and the therapist had addressed the three identified problem areas, accom- 
plished the goals established in Visit 1, and developed a problem-solving approach that Mrs. C. could generalize to other emerging issues such as incontinence.

\section{Intervention Documentation}

Documentation of therapeutic practice and client benefit becomes increasingly critical as occupational therapists must account for their activities and service effectiveness. Figure 1 shows a form that documents intervention for Mrs. C. in one problem area, that of Mr. C.'s repetition of questions. In a research study, we developed and tested this form for documenting the planning and implementation process within each intervention visit. The form provides the therapist with a graphic delineation of five aspects of treatment: (a) each problem behavior addressed during the intervention, (b) the number and range of management approaches used by the caregiver and an indication of effectiveness, (c) the range of environmental strategies introduced by the caregiver and therapist, (d) the time frame in which strategies are accepted by the caregiver, and (e) the time frame in which ineffective strategies are eliminated. The form also provides an ongoing treatment record to discern those problem areas that are effectively addressed across cases and those that necessitate additional effort or alteration in the therapist's strategy.

The research study in which this document was used evaluated intervention strategies developed during treatment and the extent to which these strategies were accepted by caregivers and continued over the five intervention visits. Table 1 lists 17 distinct solutions, arranged in descending order of frequency of use, that were implemented by 17 caregivers in the study. These solutions involved modification or manipulation of one or more environmental layers and were identified as effective by the therapist because a desired change in the care recipient's behavior was achieved. Effectiveness was determined on the basis of the caregiver's self-report and the therapist's observation in each visit. Development and implementation of these effective solutions occurred through independent problem solving by the caregiver, a direct suggestion by the therapist, or collaboration by the caregiver and therapist. As shown in Table 1, such solutions as graded assistance (12\%), encouragement of simple work and leisure tasks (10\%), use of formal supports $(10 \%)$, and preparation of the area with needed objects $(10 \%)$ were the most frequently used solutions; solutions such as eliminating clutter (3\%) and identifying objects with visual cues $(3 \%)$ were used less frequently. These

\section{Caregiver Number 21031}

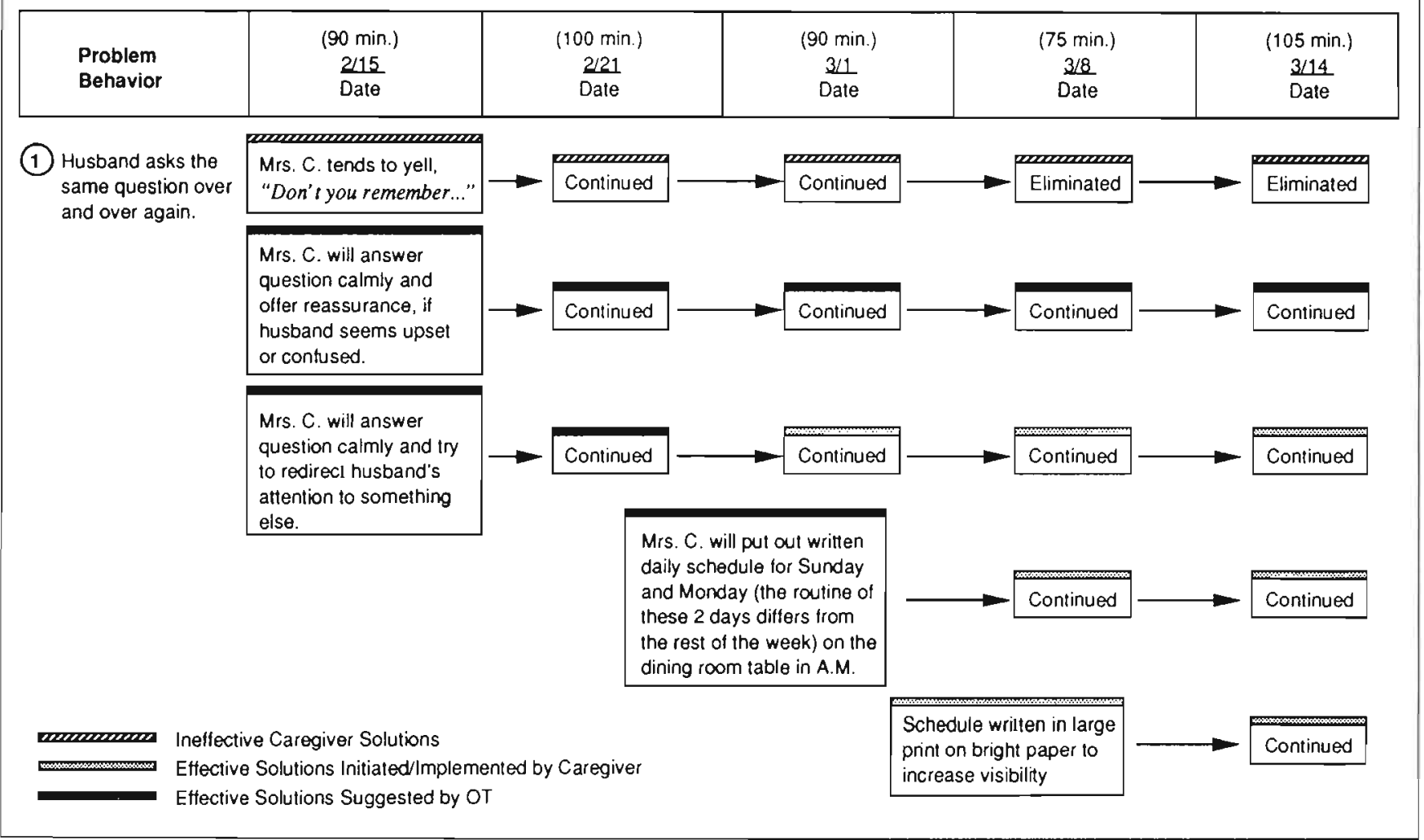

Figure 1. The treatment documentation sheet. Patterned boxes differentiate between effective and ineffective care strategies and their continuation or elimination over the intervention period. Note. OT = occupational therapist. 
Table 1

Effective Caregiver Solutions and Frequency of Use $(N=17)$

\begin{tabular}{|c|c|c|}
\hline Solution & $\begin{array}{c}\text { Number of } \\
\text { Times } \\
\text { Used }^{\text {a }}\end{array}$ & $\begin{array}{l}\% \text { of Total } \\
\text { Solutions } \\
\text { Implemented }\end{array}$ \\
\hline Use graded assistance & 33 & 12.0 \\
\hline Identify/encourage simple work and & & \\
\hline leisure tasks & 27 & 10.0 \\
\hline Use formal supports & 27 & 10.0 \\
\hline Prepare area with needed objects & 27 & 10.0 \\
\hline $\begin{array}{l}\text { Use safety precautions (e.g., locked doors, } \\
\text { nightlight, ID bracelet) }\end{array}$ & 18 & 7.0 \\
\hline Use tactile guidance/demonstration & 18 & 7.0 \\
\hline Use clear verbal instructions & 18 & 7.0 \\
\hline Convey calm and approving attitude & 17 & 6.5 \\
\hline $\begin{array}{l}\text { Establish and communicate a regular } \\
\text { routine }\end{array}$ & 15 & 6.0 \\
\hline Use commode/adaptive equipment & 12 & 4.0 \\
\hline $\begin{array}{l}\text { Use energy conservation and pacing } \\
\text { (caregiver and care recipient) }\end{array}$ & 12 & 4.0 \\
\hline Use informal supports & 11 & 4.0 \\
\hline Use caregiver education opportunities & 9 & 3.0 \\
\hline $\begin{array}{l}\text { Identify objects and their use through } \\
\text { visual cues }\end{array}$ & & 3.0 \\
\hline Eliminate clutter & 9 & 3.0 \\
\hline Use mattress pads/absorbent pads & 5 & 2.5 \\
\hline Concrol fluid intake & 3 & 1.0 \\
\hline Total & 270 & 100.0 \\
\hline
\end{tabular}

${ }^{a}$ As reported by therapist during Visits 1 through 5 .

approaches to behavioral problems may be more difficult for caregivers to incorporate into their routine or may not be viewed by caregivers as effective. Future clinical studies are needed to fully describe how caregivers select problem-solving approaches and to develop and test occupational therapy strategies for assisting caregivers in using a greater range of effective solutions. Furthermore, determining the comparative effectiveness of each management approach and examining the relative effect of the therapist's suggestions, caregiver-initiated approaches, and joint solutions would provide important insights from which to guide occupational therapy practice.

\section{Practice Considerations}

Occupational therapists offer a unique and critical contribution to helping caregivers maintain elderly persons with dementia in the home. Working with caregivers in their home offers a new consultative model of practice and presents three challenges to the profession. The first challenge is to establish a mechanism for payment for such services. A critical limitation to this intervention approach is that to date, occupational therapists cannot be reimbursed by third-party payers for these services; therefore, such services must be developed in tandem with other types of hospital or community-based programs that can absorb the costs. Hospitals experimenting with diversification of services in geriatric long-term care may endorse such an approach as part of a broader com- petitive marketing campaign to capture the geriatric consumer (Capitman et al., 1988). Although current congressional discussions and legislative hearings may expand reimbursable services to this population, there is currently no mechanism in place to do so. Home care therapists are perhaps in the best position to adopt these intervention principles and may receive Medicare reimbursement for documenting improved functioning of the care recipient. In addition, therapists in private practice can market this service model to clients who pay their own expenses and can maintain treatment documentation that supports expanding reimbursement at the state and federal levels.

The second challenge to the profession is to develop innovative educational models to train therapists to use this framework. Intervention effectiveness depends on the therapist's ability to assume and understand the caregiver's perspective, creatively adapt the principles of competence-environmental press to specific household arrangements, and suspend a medical model framework while collaborating with persons from diverse socioeconomic and cultural backgrounds. Such treatment assumptions necessitate the development of educational models that emphasize team assessment and treatment approaches, expose therapists to treatment in the home, and orient therapists on assuming a caregiver or insider perspective to jointly derive meaningful and relevant care management strategies.

The third challenge to the profession is to further develop and refine therapeutic strategies that address the multiple needs of caregivers as identified by caregivers. The intervention methods described here may work for one group of caregivers but not for all. These methods may have to be extended, modified, and adjusted to enhance the well-being of other caregiver groups. An evaluation of the relative effectiveness of specific environmental solutions for particular caregiver groups warrants further research. Future studies must also examine the interactive effects of time, experience, and caregiver stress on the ability of a specific caregiver to benefit from this or any other type of intervention.

\section{Conclusion}

This paper presented an intervention approach designed to enhance caregiver use of the environment to solve behavioral problems associated with a person with dementia. The intervention is grounded in a competenceenvironmental press framework and the principle of collaboration. The documentation form developed for the intervention provides an ongoing evaluative tool to determine therapeutic effectiveness, rate of caregiver change, and those problem areas that pose a particular challenge to the therapist and caregiver.

This intervention approach offers three potential benefits. First, the effective application of principles of the competence-environmental press model may lead to 
decreased caregiver stress and an improved sense of efficacy in the caregiver's ability to manage daily behavioral problems. Bandura's $(1977,1982)$ study of association between efficacy and competence demonstrates a strong positive relationship between sense of efficacy and one's actual performance or ability to accomplish tasks. Conversely, experiences of mastery or achievement reinforce expectations of efficacy (Bandura, 1977).

Second, the intervention may have long-term benefits. The expansion of a caregiver's ability to solve problems may enable him or her to generalize environmental strategies introduced during the intervention phase to new problem behaviors that emerge over time. Thus, one carryover effect of the intervention may be to prolong caregivers' ability to manage progressive behaviors of the person with dementia. Telephone interviews with selected caregivers after 3 months of participation in this service model indicated that their understanding of environmental influences was enhanced and that they were able to apply the skills developed during the intervention to other problem situations several months after the intervention had ended (Gitlin \& Corcoran, 1991b). The longterm benefits of the service for both the caregiver and care recipient need to be systematically tested.

Third, the concept of collaboration is especially compelling in a community-based service model that recuuires caregivers to develop skills to adapt their physical and social environments. The concept of a client-centered and collaborative approach to care has emerged in the occupational therapy and health care literature as a pivotal factor to assure treatment efficacy (Peloquin, 1990; Shelton et al., 1989). However, these relationships and the effectiveness of collaboration need continued testing Such research will also provide the necessary evidence to support development of a payment structure and health service provision system that includes the critical perspective and skills of occupational therapists.

\section{Acknowledgments}

We thank Desiree Burgh, Susan I.einmiller otRı. and Karen Schaumann, orr, for their valuable work on this project.

The intervention was developed and tested through a 1 year training grant funded by TirLawyn Consortium and a 2-vear research study supported by the American Occupational Therapy Foundation

\section{References}

American Association of Retired Persons. (1988). National sumey of caregivers: Final report. Washington, DC: Author.

Ansello, E., King, N. R., \& Taler, G. (1986). 'The environmental press model: A theoretical framework for intervention in elder abuse. In K. Pillemer \& R. S. Wolf (Eds.), Elder abuse: Conflict in the family (pp. 314-329). Dover, Mass: Auburn House.

Anthony-Bergstone, R., Zarit, S. H., \& Garz, M. (1988). Symptoms of psychological distress among caregivers of dementia patients. Psychology and Aging, 3(3), 245.
Bandura, A. (1977). Self-efficacy: Toward a unifying theory of behavioral change. Psychological Review, 84(2), 191-215.

Bandura, A. (1982). Self-efficacy mechanism in human agency. American Psychologist, 37(2), 122-147.

Barris, R., Kielhofner, G., Levine, R. E., \& Neville, A. (1985). Occupation as interaction with the environment. In G. Kielhofner (Ed.), A Model of Human Occupation: Theory and application (pp. 42-62). Baltimore: Williams \& Wilkins.

Barusch, A. S., \& Spaid, W. M. (1989). Gender differences in caregiving: Why do wives report greater burden? Gerontologist, 29, 667-676.

Brody, E. M. (1981). Women in the middle and family help to older people. Gerontologist, 21, 471-480.

Burdz, M. P. (1988). Effects of respite care on dementia and nondementia patients and their caregivers. Psychology and Aging, 3(1), 38-42.

Capitman, J., Protras, J., MacAdam, M., Leutz, W., Westwater, D., \& Yee, D. (1988). A descriptive framework for new hospital roles in geriatric care. Healtb Care Financing Review, 10, 17-25.

Chiou, I. L., \& Burnett, C. N. (1985). Values of activities of claily living: A survey of stroke patients and their home therapists. Physical Therapy, 65, 901-906.

Clark, N. M. \& Rakowski, W. (1983). Family caregivers of older adults: Improving helping skills. Gerontologist, 23, 637-642

Corbin, J. M., \& Strauss, A. (1988). Unending work and care. San Francisco: Jossey-Bass.

Corcoran, M. A., \& Barrett, D. (1987). Using sensory incegration principles with regressed elderly patients. Occupational Therapy in Health Care, 4(2), 119-128.

Corcoran, M. A., \& Gitlin, L. (1991). Environmental influences on behavior of the elderly with dementia: Principles for intervention in the home. Physical and Occupational Therapy in Geriatrics, 4(34), 5-22.

Crossman, L., London, C., \& Barry, C. (1981). Older women caring for disabled spouses: A model for supportive services. Gerontologist, 21, 464-470.

Dura, J. R. \& Kiecolr-Glaser, J. K. (1990). Sample bias in caregiving research. Joumal of Gerontology: Psychological Sciences, 45, 200-204

Edwards, D. F., \& Baum, C. M. (1990). Caregiver burden across stages of denentia. Occupational Therapy Practice, $2(1), 17-31$.

Gallagher, D. E. (1985). Intervention strategies to assist caregivers of frail elders: Current research status and future research directions. Annual Review of Gerontology and Geriatrics, 5, 249-282.

Gallagher, D., Rappaport, M., \& Benedict, A. (1985, November). Reliability of selected interview and self-report measures with fomily caregivers. Paper presented at the annual meeting of the Gerontological Society of America, New Orleans, LA.

Gendron, C. E., Poitras, I. R., Engels, M. L., Dastoor, D. P., Sirota, S. E., Barza, S. L., Davis, J. C., \& Levine, N. B. (1986). Skills tlaining with supporters of the demented Joumal of the American Geriatrics Society, 34, 875-880.

Gitlin, L.. \& Corcoran, M. A. (1991a). Environmental modification to manage difficult bebavior: A bome intervention for caregivers. Final Report, American Occupational Therapy Foundation. Manuscript submitted for publication.

Girlin, L., \& Corcoran, M. A. (1991b). Focus on collaboration: Training occupational therapists in the care of the elderly with dementia and theit caregivers. Educational Gerontology, 17. $591-605$.

Haley, W. E. (1991). Caregiver intervention programs: The moral equivalent of free haircuts? Gerontologist, 31, 7-8.

Haley, W. E., Brown, S. L., \& Levine, E. G. (1987). Experi- 
mental evaluation of the effectiveness of group intervention for dementia caregivers. Gerontologist. 27, 376-382.

Hall, G. R., \& Buckwalter, K. C. (1987). Progressively lowered stress threshold: A conceptual model for care of adules with Alzheimer's diseasc. Archives of Psychiatric Nursing. 1, $399-406$

Hanft, B. (1989). The changing environment of early intervention services: Implications for practice. In B. Hanft (Ed.), Family centered care (pp. 3-12). Rockville, MD: American Occupational Therapy Association.

Hasselkus, B. (1988). Meaning in family caregiving: Perspectives on caregiver/professional relationships. Gerontologist, 28, 686-690.

Hiatt, L. G. (1982, Spring). The environment as a participant in health care. Journal of Long-Term Care Administra. tion, 1-17.

Kaye, L., \& Applegate, J. S. (1990). Men as elcler caregivers: A response to changing families. American Joumal of Orbopsycbiatry, 60(1), 86-95.

Kiernat, J. M. (1982). Environment: The hictden modality Joumal of Pbysical and Occupational Therapy in Geriatrics, 2(1), 3-12

lawton, M. P. (1989a). Behavior-relevant ecological factors. In K. W. Schaie \& C. Schooler (Eds.), Social structure and aging (pp. 57-78). Hillside, NJ: Erlbaum.

Lawton, M. P. (1989b). Environmental proactivity in older people. In V. L. Bengscon \& K. W. Schaie (Eds.), The course of later life (pp. 15-23). New York: Springer.

Lawton, M. P., Brody, E. M., \& Saperstein, A. R. (1989). A controlled study of respite service for caregivers of Alzheimer's patients. Gerontologist, 29,8-16.

Lawton, M. P., \& Nahemow, l. (1973). Ecology and the aging process. In M. P. Lawton \& L. Nahemow (Eds.), Psychology of adult development and aging (pp. 619-674). Washington, DC: American Psychological Association.

Levine, R. E., Corcoran, M. A., \& Gitlin, L. (in press). Community home health care. In H. L. Hopkins \& H. D. Smith (Eds.), Willard and Spackman's occupational therapy (8th ed., pp. 756-780). Philadelphia: Lippincott.

Levy, L. L. (1987). Psychosocial intervention and dementia: The cognitive disability perspective, part 2. Occupational Ther apy in Mental Health, 7(6), 13-36.

Lovett, S., \& Gallagher, D. E. (1988). Psychoeducational interventions for family caregivers: Preliminary efficacy data Behavior Therapy, 19, 321-330.

Mace, N. L., \& Rabins, P. V. (1981). The 36-hour day. Baltimore: Johns Hopkins.

Miller, B. (1987). Gender and control among spouses of the cognitively impaired: A research note. Gerontologist, 27, $447-453$

Paire, J. A., \& Karney, R. J. (1984). The effectiveness of sensory stimulation for geropsychiatric inpatients. American Joumal of Occupational Therapy, 38, 505-509.

Parmalee, P. A., \& Lawton, M. P. (1990). The design of special environments for the aged. Handbook of the psychology of aging (3rd ed.). San Diego: Academic Press.

Peloguin, S. M. (1990). The patient-therapist relationship in occupational therapy: Understanding visions and images. American foumal of Occupalional Therapy, 44, 13-21.
Pepper Commission (U.S. Bipartisan Commission on Comprehensive Health Care) (1990). A call for action. Washington, DC: U.S. Government Printing Office, Pub No. 101-114. Perlman, H. H. (1973). Relationship: The heart of betping. Chicago: Iniversity of Chicago Press.

Pinkston, E. M., \& linsk, N. l. (1086). Behavioral family intervention with the impaired elderly. Gerontologist, 24, 576-583.

Pruchno, R. A., Michaels, J. E., \& Potashnik, S. L. (1990). Predictors of institutionalization among Alzheimer's disease victims with caregiving spouses. Joumal of Gerontology: Social Sciences, 45, 5259-5266.

Pynoos, J., Cohen, E., David, L. J., \& Bernhardt, S. (1987). Home modifications: Improvements that extend independence. In V. Regnier \& J. Pynoos, (Eds.), Housing the aged (pp. 277-303). New York: Flsevier Science.

Pynoos, J., Cohen, E., \& Lucas, C. (1988). The caring bome booklet: Environmental coping strategies for Alzheimer's caregivers, Los Angeles: Andrus Gerontology Center, Program in Policy and Services Research.

Rodeheaver, D., \& Datan, N. (1988). The challenge of double jeopardy: Toward a mental health agenda for aging women. American Psychologist, 43, 648-654.

Select Subcommittee on Aging, House of Representatives. (1987). Developments in aying. Washington, DC: U.S. Government Printing Office, Pub No. 100-291.

Shelton. 'T., Jeppson, E., \& Johnson, B. (1989). Implementing family centered care. In B. Hanft (Ed.), Family centered care (pp. 63-66). Rockville, MD: American Occupational Therapy Association.

Sherman, S. R., Ward, R. A., \& LaGory, M. (1988). Women as caregivers of the elderly: Instrumental and expressive support. Social Work, 33, 164-167.

Silven, D., DelMaestro, S., Gallagher, D., Lovett, S., Benedict, A., Rose, J., \& Kwong, K. (1986, November). Changes in depressed caregivers symptomatology through psycboeducational interventions. Paper presented at the Annual Scientific Meeting of the Gerontological Society of America, Chicago

Smith, G. C., Smith, M. F., \& Toseland, R. W. (1991) Problems identified by family caregivers in counseling. Gerontologist, 31, 15-22.

Stone, R., Cafferata, G. L.., \& Sangl, J. (1987). Caregivers of the frail elderly: A national profile. Gerontologist, 27, 616-626.

Toseland, R. W., Rossiter, C., \& Labrecque, M. (1989). The effectiveness of peer-led and professionally-led groups to support caregivers. Gerontologist, 29, 465-471

Whitlatch, M. S., Zarit, S. H., \& von Eye, A. (1991). Efficacy of interventions with categivers: A reanalysis. Gerontologist, 31, 9-14.

Wilson, V. (1990). The consequences of elderly wives caring for disabled husbands: Implications for practice. Social Work, 35, 417-421

Young, R. F., \& Kahana, F. (1989). Specifying caregiver outcomes: Gender and relationship aspects of caregiving strain Gerontologist. 29, 660-666.

Zarit, S. H., Anthony, C. B., \& Boutsellis, M. (1987). Interventions with caregivers of dementia patients: Comparison of two approaches. Psycbology and Aging, 2, 225-232. 